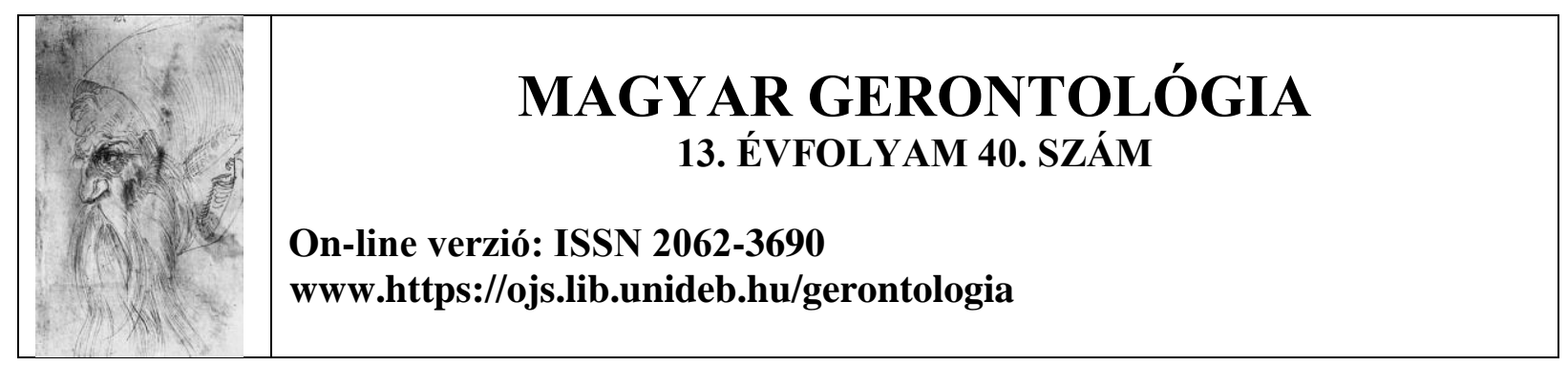

\title{
COMPARISON OF SOCIODEMOGRAPHIC CHARACTERISTICS IN NURSING HOME RESIDENTS AND COMMUNITY-DWELLING ELDERS
}

\author{
Arzu Yüksel*, Emel Bahadir Yilmaz**, Cansu Esra Kesekci*** \\ * Aksaray University, Faculty of Health Sciences, Department of Nursing, Turkey \\ ** Giresun University, Faculty of Health Sciences, Department of Nursing, Turkey \\ *** Silivri State Hospital, Children's Service, Turkey
}

Keywords: Older people, nursing home, community-dwelling, geriatric nursing

\begin{abstract}
Purpose: This study aimed to compare the sociodemographic characteristics in nursing home residents and community-dwelling elders.

Methods: This descriptive study consisted of 342 older people between October and November 2019 (nursing home $=79$, community-dwelling $=263$ ). The data were collected by "Questionnaire Form for Individuals Living in Nursing Homes" and "Questionnaires for Individuals Living in Community-Dwelling." Comparisons between groups were made with the chi-square test. Descriptive characteristics were presented as numbers, percentage, mean, standard deviation, min. and max. scores.

Results: The average age of the elderly living in a nursing home was 77.35 \pm 7.40 (min: 66, max: 97). Before coming to the nursing home, $38.0 \%$ lived with their spouses. The average age of community-dwelling older people was 70.90 \pm 5.57 (min: 65, max: 88). Of communitydwelling older people, $81.7 \%$ lived with their families. There was a significant difference between both groups regarding age, income status, having a child, having a physical disability,
\end{abstract}


using dentures, ability to maintain activities of daily living, self-confidence, sleep problems, social activity, smoking rates, and history of visiting a nursing home $(\mathrm{p}<0.05)$.

Conclusion: Compared to the community-dwelling older people, the elderly living in a nursing home were more senior, lonely, had a lower income, had higher physical disabilities, had lower social activity and self-confidence, had more sleep problems, and smoked.

\section{Introduction}

The need for nursing homes in Turkey has increased in recent years. While the population aged 65 and over, considered the elderly population, was 6 million 495 thousand 239 people in 2015 , it increased by $22.5 \%$ in the last five years. It reached 7 million 953 thousand 555 people in 2020. While the proportion of the elderly population in the total population was $8.2 \%$ in 2015 , it increased to $9.5 \%$ in 2020 (Turkish Statistical Institute, 2021). The Ministry of Family and Social Services stated that as of September 2021, 163 nursing homes with a capacity of 16,509 provided services to approximately 14 thousand people. It was envisaged that the rate of population over the age of 65 to the whole population $(9.5 \%)$ will be $11 \%$ in $2025,12.9 \%$ in $2030,16.3 \%$ in $2040,22.6 \%$ in 2060 , and $25.6 \%$ in 2080. Therefore, by the end of 2023, 23 nursing homes with a capacity of 2.320 will be put into service (Sert-Karaaslan, 2021).

Because older adults have a respectable place and authority in the traditional family structure, being placed in a nursing home voluntarily or by their children is generally not seen as a situation they are fully ready for and can easily accept. In addition, the "inadequate and wrong policies" of the relevant public institutions limited the preference of institutional care services such as nursing homes. However, especially in recent years, the changes in the living conditions, the education levels of the individuals, and the developments in different areas have increased the number of individuals who accept nursing homes as a social necessity (Artan \& Irmak, 2018).

It is accepted that Turkish society sees the nursing home as the last place that the elderly and their families will think of out of desperation only when it is necessary for socio-economic reasons. Society sees the nursing home as the most suitable option where the elderly, who have no one and financial means, are sheltered, cared for, and fed (T.R. Prime Ministry General Directorate of Social Assistance and Solidarity, 2006). In recent years, rapid changes in Turkey have also affected the family as a part of society. In modern societies, the traditional family gradually disappeared with industrialization and urbanization. The nuclear family replaced the 
traditional family, and nursing homes were needed for the elderly out of this union (EbadiAsayesh \& Özben, 2019).

Studies were carried out with the elderly living in nursing homes. According to a study, before the elderly started living in a nursing home, 58\% were alone, $20 \%$ lived with their daughter, $12 \%$ lived with their son, $10 \%$ lived with their spouse (Artan \& Irmak, 2018). According to another study, $38.1 \%$ of the elderly lived alone, $18.3 \%$ lived with their married children, and $2.2 \%$ lived with their single children before they came to the nursing home. The reasons forcing the elderly to choose nursing home life were their desires $25.3 \%$, not taking care of their children 23\%, and loneliness $16.4 \%$ (Kılıç \& Şelimen, 2017). The reasons for the elderly to stay in nursing homes were financial difficulties (72\%), not being able to take care of themselves in daily life (67\%), the desire not to be a burden to the family (52\%), and the feeling of loneliness (45\%) (T.R. Prime Ministry General Directorate of Social Assistance and Solidarity, 2006).

Studies on the subject were carried out only with the elderly living in nursing homes. Therefore, this study aimed to compare the sociodemographic characteristics in nursing home residents and community-dwelling elders.

\section{Aim}

This study was conducted as a descriptive and comparative study to determine why older people choose a nursing home.

\section{Method}

Design

The population of the descriptive and comparative study consisted of older people living in a community-dwelling or a nursing home in the Central Anatolian Region of Turkey.

\section{Sample}

The sample consisted of 342 elderly individuals who agreed to participate in the study between October and November 2019 (nursing home $=79$, community-dwelling =263). Individuals staying in a nursing home and living outside the nursing home, over 65 years old, conscious, not having any mental problems, and not having communication difficulties were included in the sample. Ninety-six elderly individuals are living in the nursing home between the specified dates. Seven of the elderly individuals were diagnosed with Alzheimer's; one of them did not speak Turkish, three had hearing problems (also illiterate), and six did not want to answer the questionnaires. Hence, 79 elderly individuals participated in the study. Two hundred sixty-three 
elderly individuals residing outside the nursing home in Aksaray who agreed to participate in the study were reached in the same date range.

\section{Data collection tools}

Data were collected by "Questionnaire Form for Individuals Living in Nursing Homes" and "Questionnaires for Individuals Living in Community-Dwelling." The questionnaires consisted of sociodemographic characteristics, such as age, gender, having a child, social insurance, economic income, chronic disease, physical disability, continuous medication use, using dentures, brushing the denture, ability to maintain activities of daily living, self-confidence, sleep problems, having a social activity, caring for an elderly relative, and visiting a nursing home.

\section{Ethical consideration}

Before starting the study, written permissions were obtained from the Education and Publication Department of the Ministry of Family, Labor and Social Services and Aksaray University Human Research Ethics Committee (date: 19.04.2019 no: 2019/04-03). Elderly individuals participating in the research were informed about the study, and an explanation was given that individual information would be kept confidential. Then, written consent was obtained from the individuals, and data were collected in line with the principles of the Declaration of Helsinki.

\section{Data analysis}

SPSS (Statistical Package for Social Science for Windows 24.0) was used to evaluate the data. Descriptive statistics such as number, percentage, mean and standard deviation were used. In addition, the chi-square test was used to compare the descriptive characteristics of the older adults living and not staying in nursing homes. The $\mathrm{p}<0.05$ level was considered statistically significant.

\section{Results}

\section{Characteristics of older adults living in nursing home}

The average age of the elderly living in a nursing home was $77.35 \pm 7.40$ (min: 66, max: 97). Before coming to the nursing home, $38.0 \%$ lived with their spouses, and $35.4 \%$ lived alone. Of the participants, $59.5 \%$ were male, $70.9 \%$ were widowed, $73.4 \%$ had a child, $63.2 \%$ were illiterate, $54.4 \%$ had social insurance, and $62.0 \%$ had an income. 
Seventy-two percent of the participants had a chronic disease, including hypertension for $30.5 \%$, dementia for $25.6 \%$, diabetes mellitus for $15.6 \%$, and heart disease for $11.6 \%$. Of them, $16.5 \%$ had physical disability.

\section{Characteristics of community-dwelling older adults}

The average age of community-dwelling older people was $70.90 \pm 5.57$ (min: 65, max: 88). $81.7 \%$ of community-dwelling older people lived with their families. Of the participants, $70.7 \%$ were male, $74.9 \%$ were married, $96.2 \%$ had a child, $46.8 \%$ graduated from primary school, $89.4 \%$ had social insurance, and $94.7 \%$ had an income.

Approximately $62.0 \%$ of the participants had a chronic disease, including hypertension for $31.4 \%$, diabetes mellitus for $27.6 \%$, heart disease for $22.0 \%$, and respiratory disease for $9.3 \%$. Of them, $1.9 \%$ had physical disability.

\section{Comparative findings}

There was a difference in terms of some sociodemographic variables between both groups (Table 1). Of older adults staying in nursing home, $31.6 \%$ were 82 years old and above and $50.2 \%$ of community-dwelling older adults were between $65-69$ years old $(p<0.001)$. Of participants in nursing home, $73.4 \%$ had a child and $96.2 \%$ of community-dwelling older adults had a child $(\mathrm{p}<0.001)$. Of older adults staying in nursing home, $62.0 \%$ had an income and $94.7 \%$ of community-dwelling older adults had an income $(\mathrm{p}<0.001)$.

Of them in nursing home, $16.5 \%$ had a physical disability and $1.9 \%$ of community-dwelling older adults had a physical disability $(\mathrm{p}<0.001)$. Of older adults staying in nursing home, $82.3 \%$ used dentures and $66.9 \%$ of community-dwelling older adults used dentures $(p=0.009)$. Of participants in nursing home, $86.1 \%$ had ability to maintain activities of daily living and $95.8 \%$ of community-dwelling older adults had ability to maintain activities of daily living $(\mathrm{p}=0.002)$. Of participants in nursing home and community-dwelling, $22.8 \%$ and $10.6 \%$, respectively had low self-confidence $(\mathrm{p}=0.006)$. Sixty-two percent and $46.4 \%$ of participants in nursing home and community-dwelling had sleep problems, respectively ( $\mathrm{p}=0.015)$. Of them in nursing home, $67.1 \%$ had no social activity and $39.2 \%$ of community-dwelling older adults had no social activity $(\mathrm{p}<0.001)$. Smoking rates of older adults in nursing home and community-dwelling were $35.4 \%$ and $22.1 \%$, respectively ( $\mathrm{p}=0.016$ ). Of older adults staying in nursing home $11.4 \%$ of them visited a nursing home and this rate in community-dwelling older adults was 36.9 ( $\mathrm{p}<$ $0.001)$. 
Table 1. Comparison of Socio-Demographical Characteristics of Individuals Staying in Nursing Homes and Community-Dwelling

\begin{tabular}{|c|c|c|c|c|c|}
\hline \multirow[t]{2}{*}{ Characteristics } & \multicolumn{2}{|c|}{ Nursing home $(n=79)$} & \multicolumn{2}{|c|}{$\begin{array}{c}\text { Community dwelling } \\
(n=263)\end{array}$} & \multirow[t]{2}{*}{$\begin{array}{l}\text { Test/p } \\
\text { values }\end{array}$} \\
\hline & $\mathrm{n}$ & $\%$ & $\mathrm{n}$ & $\%$ & \\
\hline \multicolumn{6}{|l|}{ Gender } \\
\hline Female & 32 & 40.5 & 77 & 29.3 & \multirow{2}{*}{$\begin{aligned} x^{2} & =3.528 \\
p & =0.060\end{aligned}$} \\
\hline Male & 47 & 59.5 & 186 & 70.7 & \\
\hline \multicolumn{6}{|l|}{ Age } \\
\hline $65-69$ years old & 12 & 15.2 & 132 & 50.2 & \multirow{4}{*}{$\begin{array}{l}x^{2}=58.792 \\
p=0.000\end{array}$} \\
\hline $70-75$ years old & 21 & 26.6 & 82 & 31.2 & \\
\hline $76-81$ years old & 21 & 26.6 & 33 & 12.5 & \\
\hline$\geq 82$ years old & 25 & 31.6 & 16 & 6.1 & \\
\hline \multicolumn{6}{|l|}{ Having a child } \\
\hline Yes & 58 & 73.4 & 253 & 96.2 & \multirow{2}{*}{$\begin{aligned} \mathrm{x}^{2} & =38.247 \\
\mathrm{p} & =0.000\end{aligned}$} \\
\hline No & 21 & 26.6 & 10 & 3.8 & \\
\hline \multicolumn{6}{|l|}{ Social insurance } \\
\hline Yes & 43 & 54.4 & 235 & 89.4 & \multirow{2}{*}{$\begin{aligned} \mathrm{x}^{2} & =3.528 \\
\mathrm{p} & =0.060\end{aligned}$} \\
\hline No & 36 & 45.6 & 28 & 10.6 & \\
\hline \multicolumn{6}{|l|}{ Having income } \\
\hline Yes & 49 & 62.0 & 249 & 94.7 & \multirow{2}{*}{$\begin{array}{l}x^{2}=57.776 \\
p=0.000\end{array}$} \\
\hline No & 30 & 38.0 & 14 & 5.3 & \\
\hline \multicolumn{6}{|l|}{ Chronic disease } \\
\hline Yes & 57 & 72.2 & 164 & 62.4 & \multirow{2}{*}{$\begin{aligned} x^{2} & =2.549 \\
p & =0.110\end{aligned}$} \\
\hline No & 22 & 27.8 & 99 & 37.6 & \\
\hline \multicolumn{6}{|c|}{ Physical disability } \\
\hline Yes & 13 & 16.5 & 5 & 1.9 & \multirow{2}{*}{$\begin{aligned} \mathrm{x}^{2} & =25.810 \\
\mathrm{p} & =0.000\end{aligned}$} \\
\hline No & 66 & 83.5 & 258 & 98.1 & \\
\hline \multicolumn{6}{|c|}{ Continuous medication use } \\
\hline Yes & 56 & 70.9 & 163 & 62.0 & \multirow{2}{*}{$\begin{aligned} x^{2} & =2.094 \\
p & =0.148\end{aligned}$} \\
\hline No & 23 & 29.1 & 100 & 38.0 & \\
\hline \multicolumn{6}{|l|}{ Using dentures } \\
\hline Yes & 65 & 82.3 & 176 & 66.9 & \multirow{2}{*}{$\begin{array}{c}x^{2}=6.886 \\
p=0.009\end{array}$} \\
\hline No & 14 & 17.7 & 87 & 33.1 & \\
\hline \multicolumn{6}{|c|}{ Brushing the denture } \\
\hline Yes & 51 & 64.6 & 203 & 77.2 & \multirow{2}{*}{$\begin{aligned} x^{2} & =5.071 \\
p & =0.024\end{aligned}$} \\
\hline No & 28 & 35.4 & 60 & 22.8 & \\
\hline Ability to maint & ties of daily & & & & \\
\hline Yes & 68 & 86.1 & 252 & 95.8 & $x^{2}=9.578$ \\
\hline No & 11 & 13.9 & 11 & 4.2 & $\mathrm{p}=0.002$ \\
\hline Self-confidence & & & & & \\
\hline Yes & 61 & 77.2 & 235 & 89.4 & $x^{2}=7.689$ \\
\hline No & 18 & 22.8 & 28 & 10.6 & $\mathrm{p}=0.006$ \\
\hline Sleep problems & & & & & \\
\hline Yes & 49 & 62.0 & 122 & 46.4 & $x^{2}=5.942$ \\
\hline $\mathrm{No}$ & 30 & 38.0 & 141 & 53.6 & $\mathrm{p}=0.015$ \\
\hline Having a social & & & & & \\
\hline Yes & 26 & 32.9 & 160 & 60.8 & $x^{2}=19.097$ \\
\hline
\end{tabular}




\begin{tabular}{|c|c|c|c|c|c|}
\hline No & 53 & 67.1 & 103 & 39.2 & $\mathrm{p}=0.000$ \\
\hline \multicolumn{6}{|c|}{ Smoking } \\
\hline Yes & 28 & 35.4 & 58 & 22.1 & \multirow{2}{*}{$\begin{aligned} x^{2} & =5.787 \\
p & =0.016\end{aligned}$} \\
\hline No & 51 & 64.6 & 205 & 77.9 & \\
\hline \multicolumn{6}{|c|}{ Caring for an elderly relative } \\
\hline Yes & 52 & 65.8 & 187 & 71.1 & \multirow{2}{*}{$\begin{array}{l}\mathrm{x}^{2}=0.805 \\
\mathrm{p}=0.370\end{array}$} \\
\hline No & 27 & 34.2 & 76 & 28.9 & \\
\hline \multicolumn{6}{|c|}{ Visiting a nursing home } \\
\hline Yes & 9 & 11.4 & 97 & 36.9 & \multirow{2}{*}{$\begin{aligned} \mathrm{x}^{2} & =18.455 \\
\mathrm{p} & =0.000\end{aligned}$} \\
\hline $\mathrm{No}$ & 70 & 88.6 & 166 & 63.1 & \\
\hline
\end{tabular}

$\mathrm{x}^{2}=$ chi-square test

\section{Discussion}

The present study found that while before coming to the nursing home, $38.0 \%$ lived with their spouses, and $35.4 \%$ lived alone, $81.7 \%$ of community-dwelling older people lived with their families. Similarly, according to a study, before the elderly started living in a nursing home, $58 \%$ were alone (Artan \& Irmak, 2018). According to another study, 38.1\% of the elderly lived alone and the reasons forcing the elderly to choose nursing home life were their desires $25.3 \%$, not taking care of their children 23\%, and loneliness $16.4 \%$ (Kılıç \& Şelimen, 2017). As a result, it can be said that loneliness and inadequacy of social support resources are effective in choosing a nursing home for the elderly.

The present study determined that $(25.6 \%)$ this number is one-fourth of the elderly living in nursing homes had dementia when looking at the rates of chronic diseases. However, dementia was not found in the elderly living in the community. Dementia in the elderly in nursing homes may have started before they came here, or it may occur after they have settled here, related to the quality of the service provided. Poorer cognition and behavioral and psychological symptoms of dementia (BPSD) were consistently associated with an increased risk of nursing home admission. Most of our meta-analyses demonstrated impairments in activities of daily living as a significant risk (Toot et al., 2017). Zimmerman et al. (2012) found primarily no differences across outcomes including function, cognition, depressive symptoms, pain, morbidity, behavioral symptoms, engagement, and quality of life-based on residence in a nursing home or residential care/assisted living, other than increased hospitalization for people with mild dementia.

The present study showed that the physical disabilities of the elderly living in nursing homes are higher than those living in the community. Yuan et al. (2021) determined three physical frailty subgroups in nursing home: "mild physical frailty" (prevalence: 7.6\%), "moderate physical frailty" (44.5\%), and "severe physical frailty" (47.9\%). Marmeleira et al. (2017) 
defined that nursing home residents had low physical activity and physical fitness; physical activity and physical fitness were worse in people with cognitive impairment, and more physical activity was significantly associated with better physical fitness. Therefore, health professionals should plan and implement programs for physical therapy, social groups, and motor skills to slow down the physical disabilities of elderly individuals living in nursing homes and improve their existing capacities and skills.

According to present study, the ability to maintain activities of daily living in the elderly living in the community was higher than those in nursing homes. Parlak-Demir (2017) defined that individuals living in their homes are more independent and social in their daily living activities than those residing in a nursing home. According to Lee \& Cho (2017), activities of daily living and rehabilitation needs of the older adults who received home care improved, while the older adults who received nursing home care experienced deterioration.

The present study showed that elderly individuals living in nursing homes have lower participation rates in social activities and self-confidence than those living in the community. The individuals living in the nursing home stated that their activities in their free time renew them, develop self-confidence, and provide a socialization environment (Esentaş et al., 2018). Social participation and social networking among the elderly are highly beneficial in achieving successful and healthy aging. Engagement in social activities is accompanied by optimal cognitive and physical functioning (Ghazi et al., 2017). It is necessary to encourage the social participation and interaction of the elderly in nursing homes and create suitable environments and activities.

The study found that the participants had sleep problems. This rate is significantly higher for those living in nursing homes. Different physical and mental issues can cause sleep problems. Sleep disturbance and sleep disorders in older patients can be associated with specific comorbidities, including depression, heart failure, respiratory disorders, gastro-oesophageal reflux disease, nocturia, pain, Parkinson's disease, dementia, polypharmacy, and falls (Mc Carthy, 2021). The vast majority of older adults living in nursing homes are experiencing sleep problems. It is essential for older adults to be educated and counseled to solve the sleeping problem and for the older adults to be aware of the behaviors that may cause sleeping problems to prevent/reduce the sleeping problem (Birimoglu-Okuyan \& Bilgili, 2017). 


\section{Conclusion and suggestions}

Compared to the community-dwelling older people, the elderly living in a nursing home were more senior, lonely, had a lower income, had higher physical disabilities, had lower social activity and self-confidence, had more sleep problems, and smoked.

It was recommended that leisure activities and activity groups should be established for the elderly living in nursing homes. These activities will also contribute to their mental, social and physical capacities. Individual and group therapies should be planned to improve selfconfidence. Screening should be done at regular intervals to identify and treat physical and mental health problems.

\section{References}

Artan, T., \& Irmak, H. S. (2018). Evaluation of the perspective of aging in nursing home of elderly living in nursing homes: Sample of İstanbul Bahçelievler, Zeytinburnu and Sultangazi Nursing Home. Toplum ve Sosyal Hizmet, 29, 51-70.

Birimoglu-Okuyan, C., \& Bilgili, N. (2017). Sleep status of people in nursing home and related factors. Journal of Gerontology \& Geriatric Research, 6, 3.

Ebadi-Asayesh, F., \& Özben, M. (2019). Nursing homes and elderliness: samples from Agr1 and Istanbul. Atatürk Üniversitesi Sosyal Bilimler Enstitüsü Dergisi, 23, 849-864.

Esentaş, M., Güzel, P., Yıldız, K., \& Çokşen, M. (2018). The role of the quality of life of the participation to the time leisure time activities in nursing home. Niğde Üniversitesi Beden Eğitimi Ve Spor Bilimleri Dergisi, 12, 235-241.

Ghazi, H. F., Sutan, R., Elnajeh, M., Qader, M. A. A., \& Baobaid, M. F. (2017). The importance of social participation and networking among elderly people: short review. Journal of Management and Science, 15, 99-107.

Kılıç, Ü., \& Şelimen, D. (2017). Determination of the causes that force the elders to choose living in nursing homes. Journal of Research and Education in Nursing, 3, 73-82.

Lee, K., \& Cho, E. (2017). Activities of daily living and rehabilitation needs for older adults with a stroke: A comparison of home care and nursing home care. Japan Journal of Nursing Science, 14, 103-111.

Marmeleira, J., Ferreira, S., \& Raimundo, A. (2017). Physical activity and physical fitness of nursing home residents with cognitive impairment: A pilot study. Experimental Gerontology, 100, 63-69. 
Mc Carthy, C. E. (2021). Sleep disturbance, sleep disorders and co-morbidities in the care of the older person. Medical Sciences, 9, 31.

Parlak-Demir, Y. (2017). Kendi evinde yaşayan ve huzurevinde yaşayan yaşlı bireylerin günlük yaşam aktivitelerinin, depresyon düzeylerinin ve sosyal izolasyon durumlarının karşılaştırılması. Ankara Sağlık Hizmetleri Dergisi, 16, 19-27.

Sert-Karaaslan, Y. (2021). Until the end of 2023, 23 nursing homes with a capacity of 2 thousand 320 will be put into service. https://www.aa.com.tr/tr/gundem/2023-yilisonuna-kadar-2-bin-320-kapasiteli-23-huzurevi-hizmete-acilacak/2403145

Toot, S., Swinson, T., Devine, M., Challis, D., \& Orrell, M. (2017). Causes of nursing home placement for older people with dementia: a systematic review and meta-analysis. International Psychogeriatrics, 29, 195-208.

T.R. Prime Ministry General Directorate of Social Assistance and Solidarity. (2006). Evaluation of Social Services Provided to the Elderly: Summary Report. https://www.huzurevleri.org.tr/docs/YaslilaraSunulanSosyalHizmetlerinDegerlendiril mesi.pdf

Turkish Statistical Institute. (2021). Seniors with statistics, 2020. https://data.tuik.gov.tr/Bulten/Index?p=Elderly-Statistics-2020-37227

Yuan, Y., Lapane, K. L., Tjia, J., Baek, J., Liu, S. H., \& Ulbricht, C. M. (2021). Physical frailty and cognitive impairment in older nursing home residents: a latent class analysis. $B M C$ Geriatrics, 21, 487.

Zimmerman, S., Anderson, W., Brode, S., Jonas, D., Lux, L., Beeber, A., ... Sloane, P. (2012). Comparison of characteristics of nursing homes and other residential long-term care settings for people with dementia. Comparative Effectiveness Review, 79.

\section{Authors:}

Assoc. Prof. Arzu YÜKSEL*, Assoc. Prof. Emel BAHADIR YILMAZ**, Nurse Cansu Esra KESEKCI***

* Aksaray University, Faculty of Health Sciences, Department of Nursing, Turkey.

ORCID ID: 0000-0001-7819-2020.

** Giresun University, Faculty of Health Sciences, Department of Nursing, Turkey.

ORCID ID: 0000-0003-1785-3539. 
*** Silivri State Hospital, Children's Service, Turkey.

\section{Corresponding Author:}

Dr. Emel BAHADIR YILMAZ,

ORCID ID: 0000-0003-1785-3539.

Giresun University, Faculty of Health Sciences, Department of Nursing, Piraziz, Giresun, Turkey.

E-mail: ebahadiryilmaz@yahoo.com.

Phone: +904543101840/3008 